\title{
New data analysis methods for instrumented medium-scale monopile field tests
}

\author{
HARVEY J. BURD*, WILLIAM J. A. P. BEUCKELAERS $\uparrow$, BYRON W. BYRNE*, KENNETH G. GAVIN\$, \\ GUY T. HOULSBY*, DAVID J. P. IGOE§, RICHARD J. JARDINE\|, CHRISTOPHER M. MARTIN*, \\ ROSS A. MCADAM*, ALASTAIR MUIR WOOD $\|$, DAVID M. POTTS $\|$, \\ JESPER SKOV GRETLUND**, DAVID M. G. TABORDA $\|$ and LIDIJA ZDRAVKOVIĆ $\|$
}

\begin{abstract}
The PISA Joint Industry Research Project was concerned with the development of improved design methods for monopile foundations in offshore wind applications. PISA involved large-scale pile tests in overconsolidated glacial till at Cowden, north-east England, and in dense, normally consolidated marine sand at Dunkirk, northern France. This paper describes the experimental set-up for pile testing, with unique features of load-application mechanisms and built-in fibre optic strain gauges. New procedures are described for the interpretation of pile loading data, and specifically for providing precise interpretation of pile displacements.
\end{abstract}

KEYWORDS: design; field instrumentation; model tests; offshore engineering; piles \& piling; soil/structure interaction

\begin{abstract}
INTRODUCTION
A field testing campaign has been completed, as part of the PISA (Pile-Soil Analysis) project, to investigate the response of monopile foundations subjected to monotonic and cyclic lateral loads (Byrne et al., 2015, 2017; Zdravković et al., 2019a). The test conditions and pile dimensions were intended to be representative (albeit at reduced scale) of design conditions for monopile foundations for offshore wind turbines in the North Sea. Tests were conducted at two onshore sites: an overconsolidated clay till site at Cowden in the UK (Byrne et al., 2019) and a dense/medium dense sand site at Dunkirk in France (McAdam et al., 2019).

The test piles were instrumented with inclinometers, strain gauges, displacement transducers and a load cell. This paper describes new procedures developed to process the raw data $(a)$ accounting for measurement errors, and $(b)$ exploiting redundancy in the measurements. Some details are also given here of further aspects of pile performance (e.g. distribution of bending moment) used in later papers (Byrne et al., 2019; McAdam et al., 2019) for further analysis. The analysis procedures are demonstrated for one of the piles tested at Cowden: a pile with diameter $D=0.762 \mathrm{~m}$ and embedded length-to-diameter ratio, $L / D$, of 10 .
\end{abstract}

Manuscript received 5 March 2018; revised manuscript accepted 9 July 2019. Published online ahead of print 15 November 2019.

Discussion on this paper closes on 1 March 2021, for further details see p. ii.

Published with permission by the ICE under the CC-BY 4.0 license. (http://creativecommons.org/licenses/by/4.0/)

* Department of Engineering Science, University of Oxford, Oxford, UK.

$\dagger$ Jan De Nul Group, Aalst, Belgium; formerly Department of Engineering Science, Oxford University, Oxford, UK.

† Delft University of Technology, Delft, the Netherlands; formerly School of Civil Engineering, University College Dublin, Dublin, Ireland.

$\S$ Trinity College, Dublin, Ireland; formerly School of Civil Engineering, University College Dublin, Dublin, Ireland.

|| Department of Civil and Environmental Engineering, Imperial College London, London, UK.

I Wood Thilsted Partners, London, UK; formerly Ørsted Wind Power, London, UK.

** Ørsted Wind Power, Copenhagen, Denmark.

\section{PILE TESTING SET-UP}

\section{Test specification}

In specifying the test programme to investigate the lateral response of stiff piles, a key parameter for investigation of monopile-soil interaction was the pile length-to-diameter ratio $(L / D)$. This was selected to vary between about 3 and 10 , as typically employed for offshore wind turbine foundations. Three pile diameters were selected, designated as small $(D=$ $0.273 \mathrm{~m})$, medium $(D=0.762 \mathrm{~m})$ and large $(D=2.0 \mathrm{~m})$. At Cowden, as elaborated in the paper by Zdravković et al. (2019a), the presence of a sand layer at a depth of approximately $12 \mathrm{~m}$ imposed a constraint on the pile length, and a maximum pile length, $L$, of about $10.5 \mathrm{~m}$ was therefore adopted at both sites. The selection of pile wall thickness, $t$, was an important aspect of the pile design process. The pile wall thickness needed to be small, to maximise the resolution from the strain gauges, but sufficiently large to ensure that yield of the pile wall did not occur - that is, that failure would occur in the soil before yielding in the pile. This ensured that, in subsequent analysis of the test data, it could be assumed that the pile remained elastic. The appropriate wall thicknesses were determined from three-dimensional (3D) finite-element analyses of each test pile (Zdravković et al., 2015).

The programme of tests was designed so that the same pile geometries, loading systems, instrumentation and data collection protocols could be employed at both sites. The medium- and large-diameter piles were installed in a twostage process, with an initial vibration stage used to embed piles to a stable depth $(1.0 \mathrm{~m}$ to $1.5 \mathrm{~m})$, followed by pile driving with a hydraulic hammer until the target embedment was reached. In contrast, the small-diameter piles were simply vibrated to the target embedment.

In total, 14 steel, open-ended test piles were installed at each site, in the layouts shown in Fig. 1 and with geometric characteristics summarised in Table 1. A key issue in the design of the test programme was the appropriate spacing between the test piles. This was particularly important for the large-diameter piles, which were loaded by reacting the two piles against each other; if the spacing was too small then interaction effects may have become significant. Increasing the spacing, however, would increase the cost and complexity of the loading frame required. To address this issue, initial 3D finite-element analyses were conducted to determine the 


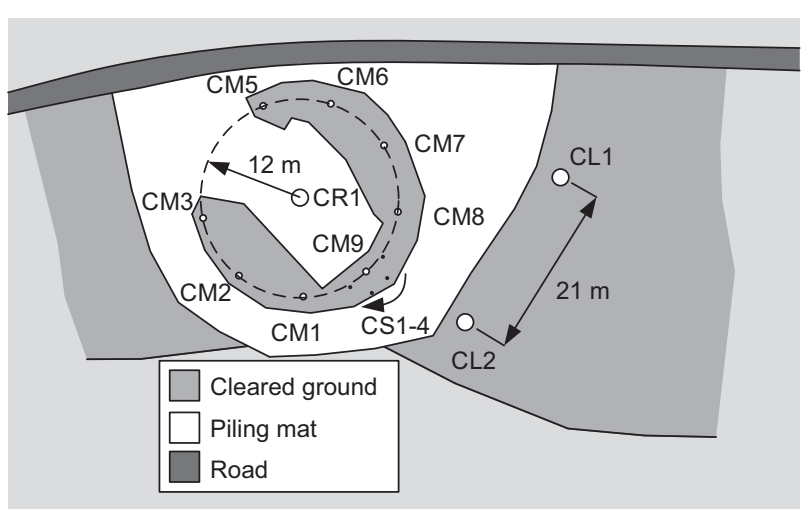

(a)

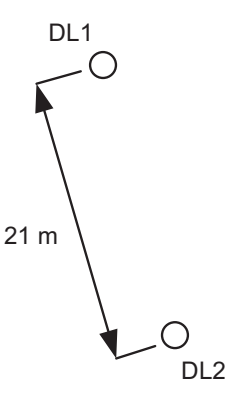

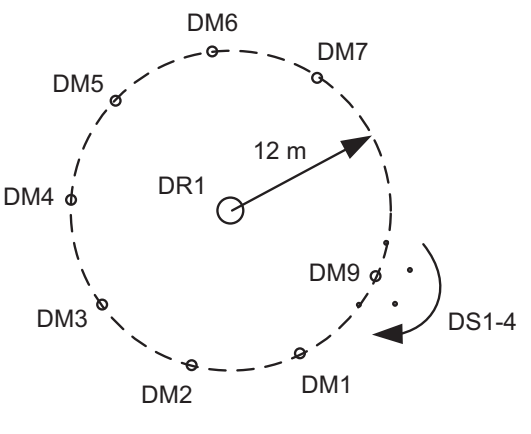

(b)

Fig. 1. Pile layout: (a) Cowden; (b) Dunkirk

Table 1. Test pile geometries and loading

\begin{tabular}{l|l|l|c|c|c|c|c|c|c}
\hline Test & Type & $D: \mathrm{m}$ & $L: \mathrm{m}$ & $L / D$ & $t: \mathrm{mm}$ & $h: \mathrm{m}$ & $h / D$ & Below-ground instruments & Piezometers \\
\hline CS1 & rate & $0 \cdot 273$ & $1 \cdot 43$ & $5 \cdot 25$ & 7 & $5 \cdot 0$ & $18 \cdot 32$ & & \\
CS2 & mon & $0 \cdot 273$ & $1 \cdot 43$ & $5 \cdot 25$ & 7 & $5 \cdot 0$ & $18 \cdot 32$ & & \\
CS3 & mon & $0 \cdot 273$ & $2 \cdot 18$ & 8 & 7 & $5 \cdot 0$ & $18 \cdot 32$ & & \\
CS4 & mon & $0 \cdot 273$ & $2 \cdot 73$ & 10 & 7 & $5 \cdot 0$ & $18 \cdot 32$ & & $*$ \\
CM8 & mon & $0 \cdot 762$ & $2 \cdot 27$ & $2 \cdot 98$ & 10 & $9 \cdot 92$ & $13 \cdot 02$ & & $*$ \\
CM2 & mon & $0 \cdot 762$ & $2 \cdot 24$ & $2 \cdot 93$ & 10 & $10 \cdot 06$ & $13 \cdot 20$ & $*$ & $*$ \\
CM9 & mon & $0 \cdot 762$ & $3 \cdot 98$ & $5 \cdot 23$ & 11 & $9 \cdot 98$ & $13 \cdot 10$ & $*$ & $*$ \\
CM6 & mon/cyc & $0 \cdot 762$ & $4 \cdot 01$ & $5 \cdot 26$ & 11 & $9 \cdot 98$ & $13 \cdot 10$ & $*$ & $*$ \\
CM5 & 1w-cyc & $0 \cdot 762$ & $4 \cdot 00$ & $5 \cdot 25$ & 11 & $10 \cdot 00$ & $13 \cdot 12$ & $*$ & $*$ \\
CM7 & 2w-cyc & $0 \cdot 762$ & $3 \cdot 98$ & $5 \cdot 23$ & 11 & $10 \cdot 00$ & $13 \cdot 12$ & & $*$ \\
CM1 & mon/rate & $0 \cdot 762$ & $3 \cdot 98$ & $5 \cdot 23$ & 15 & $9 \cdot 98$ & $13 \cdot 10$ & & $*$ \\
CM3 & mon & $0 \cdot 762$ & $7 \cdot 59$ & $9 \cdot 96$ & 25 & $10 \cdot 01$ & $13 \cdot 14$ & & $*$ \\
CL1 & mon/cyc & 2 & $10 \cdot 35$ & $5 \cdot 17$ & 25 & $10 \cdot 10$ & $5 \cdot 05$ & & $*$ \\
CL2 & mon/cyc & 2 & $10 \cdot 60$ & $5 \cdot 30$ & 25 & $10 \cdot 10$ & $5 \cdot 05$ & & $*$ \\
DS1 & mon & $0 \cdot 273$ & $1 \cdot 43$ & $5 \cdot 25$ & 7 & $5 \cdot 0$ & $18 \cdot 32$ & & $*$ \\
DS2 & rate & $0 \cdot 273$ & $1 \cdot 43$ & $5 \cdot 25$ & 7 & $5 \cdot 0$ & $18 \cdot 32$ & & $*$ \\
DS3 & mon & $0 \cdot 273$ & $2 \cdot 18$ & 8 & 7 & $5 \cdot 0$ & $18 \cdot 32$ & & $*$ \\
DS4 & mon & $0 \cdot 273$ & $2 \cdot 73$ & 10 & 7 & $5 \cdot 0$ & $18 \cdot 32$ & & $*$ \\
DM5 & mon & $0 \cdot 762$ & $2 \cdot 27$ & $2 \cdot 98$ & 10 & $9 \cdot 99$ & $13 \cdot 11$ & & $*$ \\
DM7 & mon & $0 \cdot 762$ & $2 \cdot 24$ & $2 \cdot 94$ & 10 & $10 \cdot 00$ & $13 \cdot 12$ & & $*$ \\
DM9 & mon & $0 \cdot 762$ & $3 \cdot 96$ & $5 \cdot 20$ & 14 & $10 \cdot 00$ & $13 \cdot 12$ & & $*$ \\
DM4 & mon & $0 \cdot 762$ & $3 \cdot 98$ & $5 \cdot 23$ & 14 & $9 \cdot 98$ & $13 \cdot 10$ & & $*$ \\
DM2 & 1w-cyc/mon & $0 \cdot 762$ & $3 \cdot 99$ & $5 \cdot 24$ & 14 & $10 \cdot 00$ & $13 \cdot 12$ & & $*$ \\
DM1 & 2w-cyc & $0 \cdot 762$ & $3 \cdot 97$ & $5 \cdot 21$ & 14 & $10 \cdot 02$ & $13 \cdot 15$ & & $*$ \\
DM6 & mon/rate & $0 \cdot 762$ & $3 \cdot 99$ & $5 \cdot 23$ & 19 & $10 \cdot 00$ & $13 \cdot 12$ & & $*$ \\
DM3 & mon & $0 \cdot 762$ & $6 \cdot 02$ & $7 \cdot 90$ & 25 & $10 \cdot 06$ & $13 \cdot 20$ & & $*$ \\
DL1 & mon/cyc & 2 & $10 \cdot 61$ & $5 \cdot 30$ & 38 & $9 \cdot 90$ & $4 \cdot 95$ & & $*$ \\
DL2 & mon/cyc & 2 & $10 \cdot 57$ & $5 \cdot 29$ & 38 & $9 \cdot 89$ & $4 \cdot 95$ & & $*$ \\
\hline
\end{tabular}

Notes: C, Cowden; D, Dunkirk; S, small diameter $(0.273 \mathrm{~m})$; M, medium diameter $(0.762 \mathrm{~m})$; L, large diameter $(2 \cdot 0 \mathrm{~m}) ; 1 \mathrm{w}-\mathrm{cyc}$, one-way cyclic loading; $2 \mathrm{w}$-cyc, symmetric two-way cyclic loading; mon, monotonic loading. The symbol * in the table indicates the incorporation of instruments/piezometers in the test pile.

likely ground movements developed during the tests (Zdravković et al., 2015). These results indicated that predicted lateral ground movements reduce significantly with radial distance from the pile, and that they become negligibly small beyond a distance of about five pile diameters. A standard minimum spacing of $10 \mathrm{D}$ for all of the test piles was therefore adopted as sufficient to minimise any pile/pile interaction effects. This approach is consistent with, for example, the model pile tests in clay described by Chandrasekaran et al. (2009), in which pile/pile interactions in a two-pile group in terms of ultimate load were only observed for pile spacings of $5 D$ and less.

After the piles were installed, a vertical extension (referred to as a 'transition piece') was fixed to the pile head (Figs 2(b) and 2(c)), except for the small-diameter piles, which were a continuous tube, as shown in Fig. 2(a). The transition piece allowed the horizontal load, $H$, to be applied at an elevation, $h$, above the ground surface, representing the typical wind or wave loading conditions on an offshore wind turbine structure. The load eccentricity, $h$, was $5 \mathrm{~m}$ for smalldiameter piles and $10 \mathrm{~m}$ for the remaining piles. Although it introduced a significant complication to the testing, it was regarded as important that the load was applied above ground, reproducing realistically both horizontal force and moment loading on an offshore monopile. Lateral monotonic loading was applied by a hydraulic actuator connected to a reaction pile, as indicated in Fig. 1; similar configurations were employed for the cyclic tests.

Four small-diameter piles (CS and DS at Cowden and Dunkirk, respectively) were principally intended to provide a check on the instrumentation, loading system and test procedure, although they also provided information on scale effects. They were subjected only to monotonic lateral loading, with a medium-diameter pile (CM9 and DM9) acting as a 


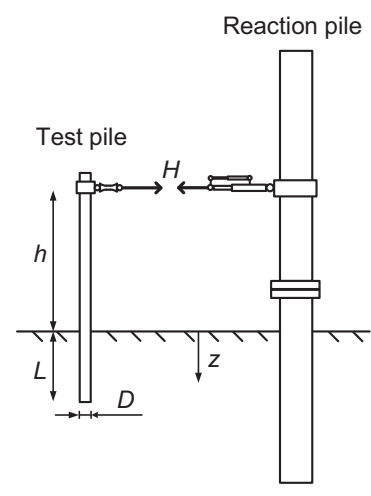

(a)

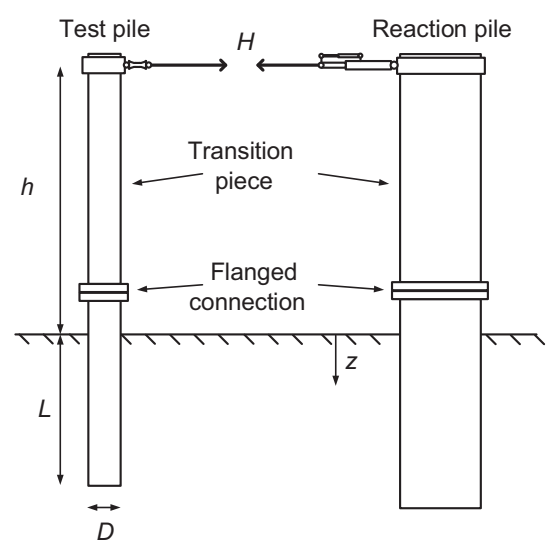

(b)

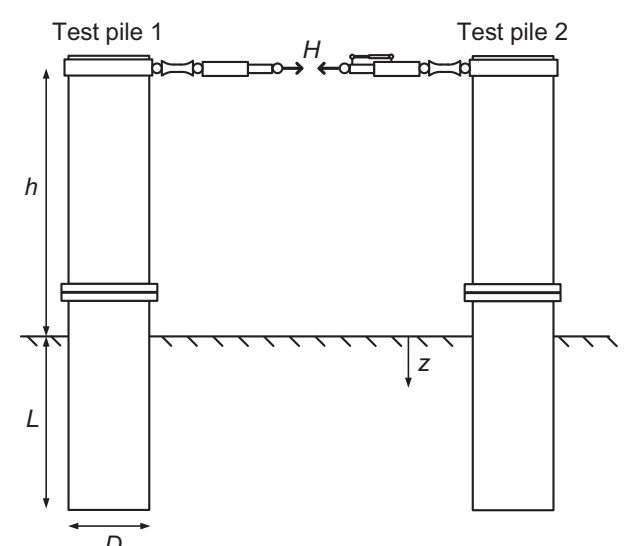

(c)

Fig. 2. Testing configuration for monotonic loading of the three pile diameters: (a) $D=0 \cdot 273 \mathrm{~m}$; (b) $D=0 \cdot 762 \mathrm{~m} ;($ c) $D=2 \cdot 0 \mathrm{~m}$

reaction pile, Fig. 2(a). Eight medium-diameter piles, arranged in a circular pattern and tested against the central $2 \mathrm{~m}$ diameter reaction pile (CR1 and DR1, Fig. 2(b)), were used to investigate a range of geometric parameters $(L / D ; h / D ; t)$ under monotonic lateral loading. Additionally, a small number of tests involved loading rate variation, unidirectional cyclic loading and bidirectional cyclic loading. Two largediameter piles were reacted against each other, Fig. 2(c), and subjected to both monotonic and cyclic loading tests.

\section{Instrumentation}

Separate specifications were developed for the above- and the below-ground instrumentation, as indicated in Fig. 3 and Table 2. The above-ground instrumentation consisted of

(a) a full-bridge aluminium body load cell to record the applied lateral load $H$

(b) microelectromechanical sensor (MEMS) inclinometers fixed to the transition piece or pile (indicated as 'point inclinometer (PI)' in Fig. 3)

(c) potentiometer displacement transducers (indicated as 'DT' on Fig. 3) attached to the 'active' and 'passive' pile faces, and fixed at the other end to an isolated reference frame system

(d) a displacement transducer mounted on the loading ram (not illustrated) to record the ram movement for the purpose of controlling the loading system.

The capacity and range of the load cells and the displacement transducers were selected individually for each pile test, based on 3D finite-element predictions of the pile response (Zdravković et al., 2015, 2019b; Byrne et al., 2017; Taborda et al., 2019).

Most of the medium-diameter piles at each site, and all of the large-diameter piles, were additionally installed with below-ground instrumentation. Two medium-diameter piles at each site (CM8, CM9, DM5 and DM9, used to prove the load control system prior to the main test programme) were installed only with above-ground instruments. Below-ground instrumentation was required to measure the strains developed in the embedded pile wall and also the pile inclination, as follows.

(a) Fibre Bragg grating sensors were used to measure the strains in the pile wall. Continuous fibre optic sensing systems were considered, but these would not provide sufficient sampling rates for the planned testing. In

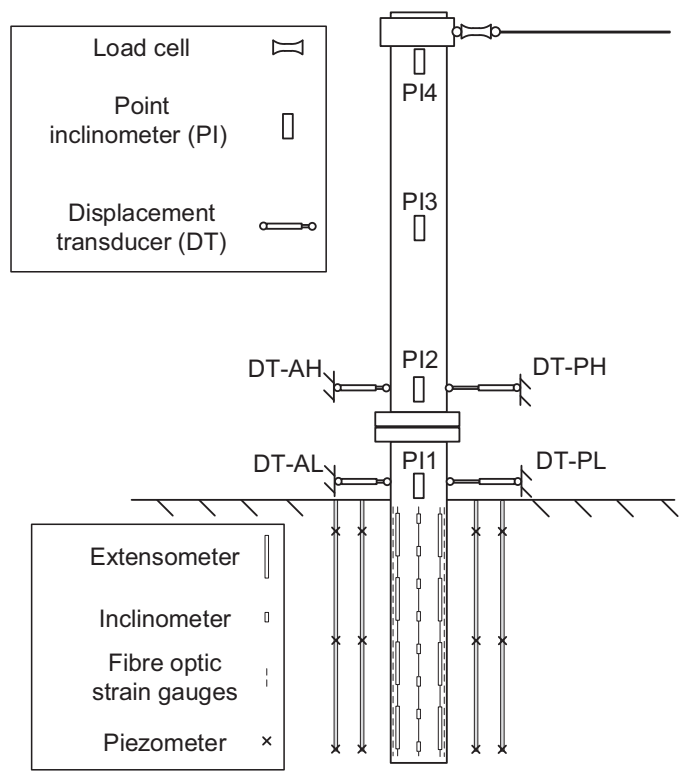

Fig. 3. Fully instrumented medium-diameter pile. Labels for displacement transducers correspond to passive low (PL), passive high (PH), active low (AL), active high $(\mathrm{AH})$ and point inclinometers (PI1-PI4). Note that for some tests the upper displacement transducers were mounted below the flanged connection rather than as shown in figure

particular, the cyclic tests conducted during the PISA test programme required a sampling rate of $10 \mathrm{~Hz}$, which was higher than the available sampling rates for continuous systems. Prior to pile installation, optical fibres containing the sensors were bonded into $5 \mathrm{~mm}$ square channels cut on the external face along the active and passive sides of the pile. The fibres were initially 'pinned' into the abraded and degreased channel with cyanoacrylate, to achieve a tensile pre-strain of 1500-2000 $\mu \varepsilon$, before being potted-in using an epoxy resin. A superficial covering of hot glue was faired to the pile outer circumference to prevent catching of the epoxy during driving.

(b) A separate strain measurement system, based on retrievable MEMS extensometers, was also employed to provide some redundancy in case of failure of the optical fibres. The MEMS extensometers were deployed by way of internal tubes welded to the passive and active faces of the pile, and were also used to deduce the below-ground pile inclination. 
The general arrangement of the below-ground instrumentation is illustrated in Fig. 4. Steel $100 \mathrm{~mm}$ square, $5 \mathrm{~mm}$ wall thickness, C-channels were seam welded to the inside of the instrumented piles for fixing of the retrievable extensometer and inclinometer systems. The inclinometer casing was fixed within the channels using a standard grout. The extensometer casing was fixed within the channels using an epoxy-based Epicon Grout M, to provide sufficient structural fixity for strain transfer. The stiffness contributions of the steel channels were relatively small, but were taken into account in calculations of the pile section second moment of area for subsequent data-processing purposes. The reduction

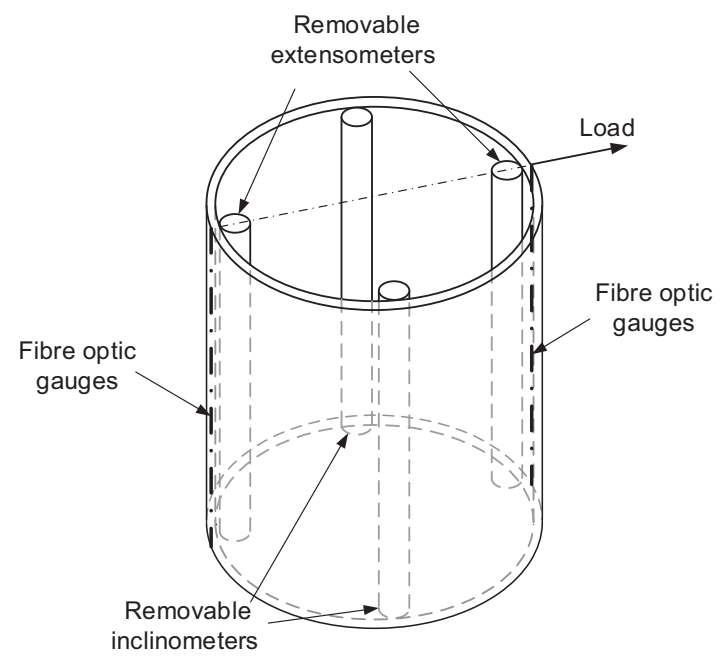

Fig. 4. Pile section featuring below-ground instrumentation in section second moment of area due to the $5 \mathrm{~mm}$ squarecut fibre optic channels was considered to be negligible.

The load and displacement measurements were logged with 16-bit analogue-to-digital resolution using a Tiab controller, which provided the load and displacement feedback for the test control. The inclinometer and extensometer sensor measurements were logged using Campbell Scientific CR1000 data loggers with 13-bit analogue-to-digital resolution. The fibre Bragg grating strain measurements were logged using a Micron Optics SM130 interrogator, with a calculated repeatable stable strain measurement accuracy of $1.7 \mu \varepsilon$. Further specification of the instrumentation is provided in Table 3.

Concerns initially existed as to whether the optical fibres would be damaged during the pile driving process. Previous testing (Doherty et al., 2015) had indicated the possibility of successfully employing fibre Bragg grating sensors in driven piles. Nevertheless, the MEMS extensometers added system redundancy by providing additional strain data in case the optical fibres were damaged during pile installation. In the event, it was found that 31 of the 32 fibre optic strain gauge strings installed in the test piles survived the driving process with no significant loss of performance.

\section{DATA LOGGING PROCEDURES}

Measurement synchronisation was achieved by periodic pulse generation and a network time protocol, shared between the various data loggers. Several measures were taken to ensure that the risk of sensor drift was minimised. Tarpaulin covers were used to protect the displacement transducers and reference frame system from solar heating. Zero offset values for each instrument were taken immediately prior to the start of loading. The ambient temperature was monitored during the monotonic test period, which typically lasted $6-8 \mathrm{~h}$. Temperature variations in all tests were

Table 2. Specification of instruments used on each pile

\begin{tabular}{|c|c|c|c|c|c|c|c|}
\hline \multirow[t]{2}{*}{ Pile } & \multirow{2}{*}{$\begin{array}{c}\text { Date } \\
\text { installed }\end{array}$} & \multirow{2}{*}{$\begin{array}{l}\text { Date } \\
\text { tested }\end{array}$} & \multirow{2}{*}{$\begin{array}{l}\text { Load cell } \\
\text { range: } \mathrm{kN}\end{array}$} & \multirow{2}{*}{$\begin{array}{l}\text { Displacement transducer } \\
\text { ranges: } \mathrm{mm}^{*}\end{array}$} & \multicolumn{3}{|c|}{ Average sensor spacing: $\mathrm{m}$} \\
\hline & & & & & Fibre optics & Inclinometer & Extensometer \\
\hline $\mathrm{CS} 1$ & $06 / 12 / 14$ & $16 / 01 / 15$ & 125 & $75(\mathrm{~L})-100(\mathrm{H})$ & - & - & - \\
\hline $\mathrm{CS} 2$ & $06 / 12 / 14$ & $22 / 01 / 15$ & 125 & $75(\mathrm{~L})-100(\mathrm{H})$ & - & - & - \\
\hline CS3 & $06 / 12 / 14$ & $28 / 01 / 15$ & 125 & $75(\mathrm{~L})-100(\mathrm{H})$ & - & - & - \\
\hline CS4 & $06 / 12 / 14$ & $20 / 01 / 15$ & 125 & $75(\mathrm{~L})-100(\mathrm{H})$ & - & - & \\
\hline CM8 & $14 / 10 / 14$ & $16 / 02 / 15$ & 1750 & $150(\mathrm{~L})-225(\mathrm{H})$ & - & - & - \\
\hline CM2 & $17 / 10 / 14$ & $07 / 04 / 15$ & 1750 & $150(\mathrm{~L})-225(\mathrm{H})$ & $0 \cdot 50$ & $0 \cdot 44$ & $0 \cdot 92$ \\
\hline CM9 & $17 / 10 / 14$ & $12 / 02 / 15$ & 1750 & $150(\mathrm{~L})-225(\mathrm{H})$ & - & - & - \\
\hline CM6 & $08 / 12 / 14$ & $10 / 03 / 15$ & 1750 & $150(\mathrm{~L})-225(\mathrm{H})$ & $0 \cdot 50$ & $0 \cdot 45$ & $0 \cdot 87$ \\
\hline CM5 & $17 / 10 / 14$ & $05 / 03 / 15$ & 125 & $50(\mathrm{~L})-225(\mathrm{H})$ & $0 \cdot 50$ & 0.45 & $0 \cdot 87$ \\
\hline $\mathrm{CM} 7$ & $05 / 12 / 14$ & $02 / 03 / 15$ & 125 & $10(\mathrm{~L})-75(\mathrm{H})$ & $0 \cdot 50$ & $0 \cdot 45$ & $0 \cdot 87$ \\
\hline CM1 & $09 / 12 / 14$ & $21 / 07 / 15$ & 1750 & $150(\mathrm{~L})-225(\mathrm{H})$ & $0 \cdot 50$ & $0 \cdot 45$ & $0 \cdot 87$ \\
\hline CM3 & $08 / 12 / 14$ & $21 / 07 / 15$ & 1750 & $150(\mathrm{~L})-225(\mathrm{H})$ & $0 \cdot 50$ & $0 \cdot 60$ & $0 \cdot 89$ \\
\hline CL1 & $06 / 12 / 14$ & $16 / 01 / 15$ & $4 \times 1750$ & $300(\mathrm{~L})-500(\mathrm{H})$ & $0 \cdot 75$ & 1.26 & $1 \cdot 24$ \\
\hline CL2 & $06 / 12 / 14$ & $22 / 01 / 15$ & $4 \times 1750$ & $300(\mathrm{~L})-500(\mathrm{H})$ & $0 \cdot 75$ & $1 \cdot 26$ & $1 \cdot 24$ \\
\hline DS1 & $08 / 11 / 14$ & $22 / 04 / 15$ & 125 & $75(\mathrm{~L})-100(\mathrm{H})$ & - & - & - \\
\hline DS2 & $08 / 11 / 14$ & $25 / 04 / 15$ & 125 & $75(\mathrm{~L})-100(\mathrm{H})$ & - & - & - \\
\hline DS3 & $08 / 11 / 14$ & $23 / 04 / 15$ & 125 & $75(\mathrm{~L})-100(\mathrm{H})$ & - & - & - \\
\hline DS4 & $08 / 11 / 14$ & $24 / 04 / 15$ & 125 & $75(\mathrm{~L})-100(\mathrm{H})$ & - & - & - \\
\hline DM5 & $10 / 11 / 14$ & $08 / 05 / 15$ & 1750 & $150(\mathrm{~L})-225(\mathrm{H})$ & - & - & - \\
\hline DM7 & $10 / 11 / 14$ & $14 / 05 / 15$ & 1750 & $150(\mathrm{~L})-225(\mathrm{H})$ & $0 \cdot 50$ & $0 \cdot 44$ & $0 \cdot 92$ \\
\hline DM9 & $10 / 11 / 14$ & $30 / 04 / 15$ & 1750 & $150(\mathrm{~L})-225(\mathrm{H})$ & - & - & - \\
\hline DM4 & $10 / 11 / 14$ & $12 / 05 / 15$ & 1750 & $150(\mathrm{~L})-225(\mathrm{H})$ & $0 \cdot 50$ & $0 \cdot 45$ & $0 \cdot 87$ \\
\hline DM2 & $10 / 11 / 14$ & $05 / 06 / 15$ & 125 & $50(\mathrm{~L})-225(\mathrm{H})$ & $0 \cdot 50$ & $0 \cdot 45$ & $0 \cdot 87$ \\
\hline DM1 & $06 / 11 / 14$ & $03 / 06 / 15$ & 125 & $10(\mathrm{~L})-75(\mathrm{H})$ & $0 \cdot 50$ & $0 \cdot 45$ & $0 \cdot 87$ \\
\hline DM6 & $14 / 11 / 14$ & $20 / 06 / 15$ & 1750 & $150(\mathrm{~L})-225(\mathrm{H})$ & $0 \cdot 50$ & $0 \cdot 45$ & $0 \cdot 87$ \\
\hline DM3 & $13 / 11 / 14$ & $20 / 06 / 15$ & 1750 & $150(\mathrm{~L})-225(\mathrm{H})$ & $0 \cdot 50$ & $0 \cdot 47$ & 0.92 \\
\hline DL1 & $08 / 11 / 14$ & $22 / 04 / 15$ & $4 \times 1750$ & $300(\mathrm{~L})-500(\mathrm{H})$ & $0 \cdot 75$ & $1 \cdot 26$ & $1 \cdot 24$ \\
\hline DL2 & $08 / 11 / 14$ & $25 / 04 / 15$ & $4 \times 1750$ & $300(\mathrm{~L})-500(\mathrm{H})$ & $0 \cdot 75$ & $1 \cdot 26$ & $1 \cdot 24$ \\
\hline
\end{tabular}

${ }^{*} \mathrm{~L}$ signifies lower transducers and $\mathrm{H}$ signifies higher transducers. 
Table 3. Specification of instruments

\begin{tabular}{|c|c|c|c|c|}
\hline Sensor type & Manufacturer & Model & Range & Logger \\
\hline Load cell & Applied Measurements Ltd & Load Link ETW & 125 and $1750 \mathrm{kN}$ & Tiab \\
\hline Displacement transducer & Penny \& Giles & MLS130 & $150 \mathrm{~mm}$ & Tiab \\
\hline Displacement transducer & Novotechnik & LWG & $\begin{array}{c}10,50,75,100,225 \\
300 \text { and } 500 \mathrm{~mm}\end{array}$ & Tiab \\
\hline Inclinometer & Geokon & 6150 & $\pm 15^{\circ}$ & CR1000 \\
\hline Extensometer & Geokon & A-9 & $\pm 12.5 \mathrm{~mm}$ & CR1000 \\
\hline Fibre Bragg grating & Micron Optics & - & - & Micron Optics SM130 \\
\hline
\end{tabular}

assessed to be small, and therefore no temperature compensation was applied. Although a small number of temperaturesensitive fibre Bragg gratings were included in the fibre optic system for possible temperature compensation purposes, some strain sensitivity was observed in these sensors. They could not, therefore, be reliably used for temperature compensation. However, data taken from these temperaturesensitive fibre Bragg gratings, logged during inactive periods, indicated, as expected, that temperature variations in the embedded pile were negligible.

\section{RAW DATA PROCESSING PROCEDURES \\ Ground-level displacement and rotation}

It is necessary to select the location of a well-defined reference point on the pile to facilitate plotting the data and comparison with results obtained from numerical analyses. Consistent with other authors (e.g. Parker \& Reese, 1970; Reese et al., 1975), a ground-level reference point is adopted in the current work. However, direct measurements of groundlevel displacement $v_{\mathrm{G}}$ and ground-level rotation $\theta_{\mathrm{G}}$ were not made during the tests (because the instrumentation could not be located precisely at ground level). A process was therefore developed to infer $v_{\mathrm{G}}$ and $\theta_{\mathrm{G}}$ from the field measurements, in a consistent manner for all tests, exploiting redundancy in the data when available. This process is described below, and illustrated using monotonic loading data from one of the Cowden medium-diameter test piles $(\mathrm{CM} 3, L / D=10$, $t=25 \mathrm{~mm}$ ) as an example (Byrne et al., 2019).

Data from the displacement transducers, load cell and inclinometer PI1 for a monotonic test on pile CM3 are shown in Fig. 5. These data present a broadly consistent picture (typical of all of the pile test data) with both the lower pair of transducers (DT-AL and DT-PL) and the upper pair (DT-AH and DT-PH) providing consistent measurements.

Three approaches were investigated to infer $v_{\mathrm{G}}$ and $\theta_{\mathrm{G}}$ from these data, as follows.

(a) Approach A - simplistically assume that $v_{\mathrm{G}}=v_{\mathrm{DT}-\mathrm{PL}}$ (where $v_{\mathrm{DT}-\mathrm{PL}}$ is the displacement recorded by DT-PL) and $\theta_{\mathrm{G}}=\theta_{\mathrm{PI} 1}$ (where $\theta_{\mathrm{PI} 1}$ is the rotation recorded by inclinometer PI1).

(b) Approach $\mathrm{B}$ - assume that $v_{\mathrm{G}}$ and $\theta_{\mathrm{G}}$ are determined from the displacement transducer readings, assuming that the portion of the pile between the ground and the upper transducer is rigid.

(c) Approach $\mathrm{C}$ - adopt a more detailed approach in which data from the above-ground instrumentation are used to determine a structural model for the above-ground structure. This model is then used to infer $v_{\mathrm{G}}$ and $\theta_{\mathrm{G}}$.

Approaches A and B are implemented, straightforwardly, using the measured data. In approach $\mathrm{C}$, the above-ground structure (pile, flanged connection and transition piece) is modelled as three separate Timoshenko beam sections, see
Fig. 6. The bending moment, $M$ (a positive moment is associated with tension on the left side of the structure), is

$$
M=-E I \frac{\mathrm{d} \psi}{\mathrm{d} z}
$$

where $E I$ is the local flexural stiffness and $\psi$ is the (clockwise) rotation of the column cross-section. The (clockwise positive) rotation of the neutral axis of the structure, $\theta=-(\mathrm{d} v / \mathrm{d} z)$ where $v$ is the lateral displacement, is

$$
\theta=\psi+\gamma_{x z}
$$

where $\gamma_{x z}$ is the shear strain, assumed in Timoshenko theory to be uniform across the cross-section and given by

$$
\gamma_{x z}=\frac{S}{\kappa A G}
$$

where $S$ is the shear force and $\kappa A G$ is the local shear stiffness (where $\kappa$ is a shear factor taken to be $0 \cdot 3$ ). It is assumed that $E=210 \mathrm{GPa}$ and $G=80.77 \mathrm{GPa}$. The flexural stiffness and cross-sectional area of the pile and transition piece $\left(E I_{\mathrm{P}}, A_{\mathrm{P}}\right.$, $E I_{\mathrm{TP}}$ and $A_{\mathrm{TP}}$, respectively) were determined from the section properties. To acknowledge the complex behaviour of the flanged connection, values of flexural stiffness and crosssectional area for the flanged connection $\left(E I_{\mathrm{F}}\right.$ and $A_{\mathrm{F}}$ respectively) were determined from the measured data using a best-fit process, such that common values of $E I_{\mathrm{F}}$ and $A_{\mathrm{F}}$ were used for the flanged connections employed for all of the medium- and large-diameter pile tests.

The bending moment, $M$, and shear force, $S$, induced in the above-ground structure are

$$
\begin{aligned}
& M=H(h+z) \\
& S=\frac{\mathrm{d} M}{\mathrm{~d} z}=H
\end{aligned}
$$

For a uniform section, these equations are integrated to give

$$
\begin{aligned}
& \theta=-\frac{H}{E I}\left(h z+\frac{z^{2}}{2}\right)+\frac{H}{\kappa A G}+a \\
& v=\frac{H}{E I}\left(\frac{h z^{2}}{2}+\frac{z^{3}}{6}\right)-\left(\frac{H}{\kappa A G}+a\right) z+b
\end{aligned}
$$

where $a$ and $b$ are parameters to be determined.

Since the above-ground structure is modelled as three separate beams, in total six parameters need to be found. These parameters are determined as follows.

(a) The lateral displacement and cross-section rotation at the flanged connection/pile and flanged connection/transition piece junctions are assumed to be continuous.

(b) The measured inclination at location PI1 and lateral displacement (average of DT-AH and DT-PH, and 


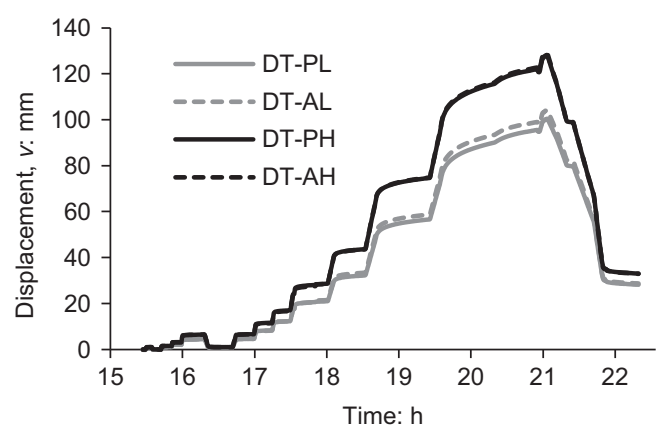

(a)

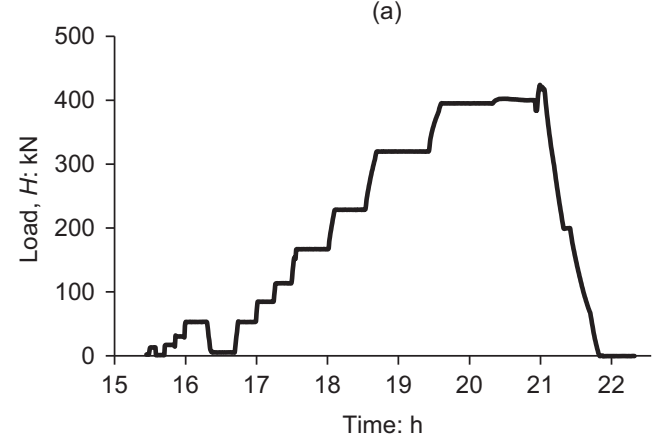

(b)

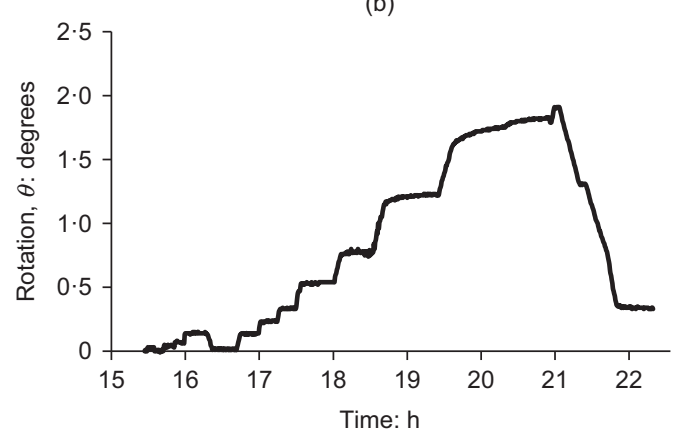

(c)

Fig. 5. Time series of measured quantities for pile CM3: (a) displacement transducers; (b) load cell; (c) PI1 inclinometer

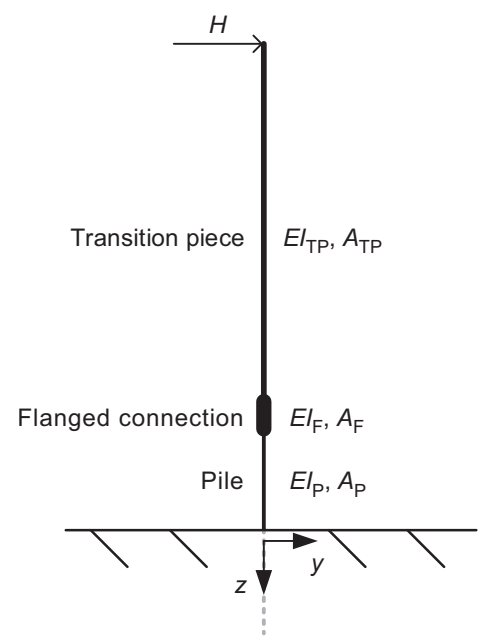

Fig. 6. Timoshenko beam model for the above-ground structure

average of DT-AL and DT-PL) at the two displacement transducer elevations are equated to the corresponding values from the structural model.

The above equations form an over-determined set; they are solved to determine the six model parameters in a weighted

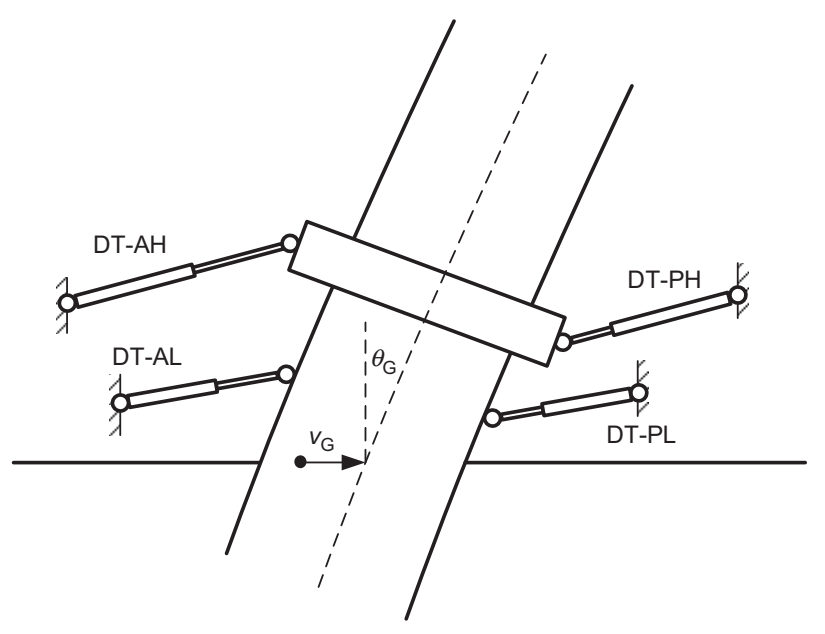

Fig. 7. Pile and transducer rotation (shown exaggerated)

least-squares sense, taking $H$ to be the value of lateral load indicated by the load cell.

It should be noted that data from the other above-ground inclinometers PI2, PI3 and PI4 were not used to determine the structural model; instead these data were used to check its predictive capabilities.

Since the displacement transducers are pinned to both the pile and the isolated reference frame, the instruments will rotate during loading (Fig. 7). To account for this, an iterative approach was adopted in which the lengths of the displacement transducers, accounting for the rotation of the pile, are computed from the current least-squares solution. The solution was iterated until the computed displacement transducer lengths converged to their measured values (within an appropriate tolerance). The ground-level displacement $v_{\mathrm{G}}$ and rotation $\theta_{\mathrm{G}}$ are determined from this converged solution.

To implement this process, it was necessary to smooth the inclinometer data. This was achieved using a zero phase digital filter, applying a Gaussian window of 41 samples width in both the forward and reverse filtering directions.

In formulating the least-squares problem, weighting factors need to be applied to the errors associated with the displacement transducer and inclinometer measurements, to ensure that each data set has an appropriate influence on the solution. It was decided that the weight given to the inclinometer data should be broadly comparable to that of the displacement transducer data at each level. Furthermore, the weighting factors are used to normalise the data, by assuming characteristic values of displacement and rotation of $v_{\mathrm{G}}=0 \cdot 1 \mathrm{D}$ and $\theta_{\mathrm{G}}=2^{\circ}$. The weighting factors applied to the inclinometer data $\left(w_{\mathrm{PI}}\right)$ and displacement transducer data $\left(w_{\mathrm{DT} j}, j=1, \ldots, 4\right)$ using this approach are

$$
\begin{aligned}
& w_{\mathrm{PI}}=\frac{1}{2^{\circ}} \\
& w_{D T j}=\frac{1}{2\left(0 \cdot 1 D-z_{\mathrm{DT} j} \tan 2^{\circ}\right)}
\end{aligned}
$$

where $z_{\mathrm{DT} j}$ is the vertical coordinate of the transducer location. Note that the factor of 2 in the denominator of equation (9) reflects the fact that the pair of displacement transducers at each height is weighted equally with the inclinometer data.

Data obtained using approaches $\mathrm{A}, \mathrm{B}$ and $\mathrm{C}$ are shown in Fig. 8. The three methods give similar results for $v_{\mathrm{G}}$. The calculated values of $\theta_{\mathrm{G}}$, however (Fig. 8(b)), indicate a dependency on the processing method. Method $\mathrm{C}$ is regarded as providing the most robust approach, since it includes redundant above-ground measurements. Also, in cases where the 
data are incomplete (e.g. due to instrument breakdown) the interpretation approach can be modified to allow values of $v_{\mathrm{G}}$ and $\theta_{\mathrm{G}}$ to be systematically determined, albeit with reduced certainty. Method $\mathrm{C}$ was therefore preferred over the other two, simpler, methods to process the data from all of the PISA field tests. Example load-displacement and loadrotation responses (determined using approach $\mathrm{C}$ to compute $v_{\mathrm{G}}$ and $\theta_{\mathrm{G}}$ ) for pile CM3 are shown in Fig. 9.

A comparison between the above-ground displacements and rotations implied by approach $\mathrm{C}$, at four values of $H$, are shown in Fig. 10. The good agreement between the structural model and the inclinometer data (not used to calibrate the model) provides further confidence in the consistency of the measured data and the robustness of approach C. A similar degree of consistency was observed in all of the other tests.

The tests were all conducted with the external loading applied in a single plane. Out-of-plane pile deformations were not expected, or measured. Any out-of-plane deformations that did occur may have affected the inclinometer measurements. However, the excellent consistency between the above-ground displacements and rotations inferred from approach $\mathrm{C}$ and the measured data suggests an absence of significant errors due to possible out-of-plane pile deformations during the tests.

\section{Embedded instrument consistency}

Figure 11 shows measured pile rotation data from the embedded inclinometers and the above-ground inclinometers at selected instants during the monotonic test on pile CM3. The results indicate a consistent measurement of inclination between the above-ground and embedded instruments.

Measurements of strain in the embedded section of the pile from the extensometers and fibre Bragg grating strain gauges

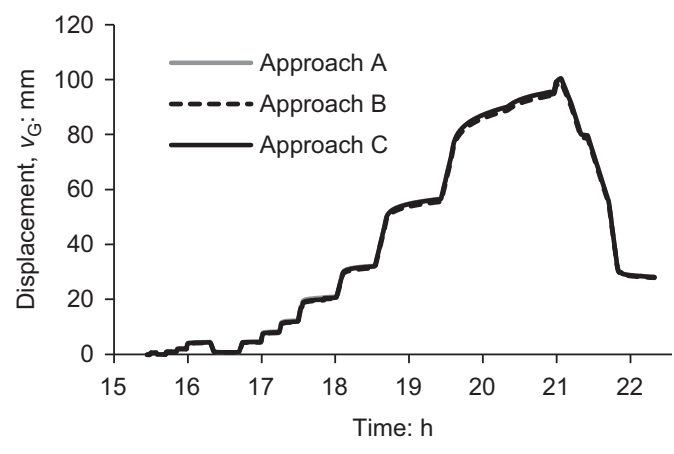

(a)

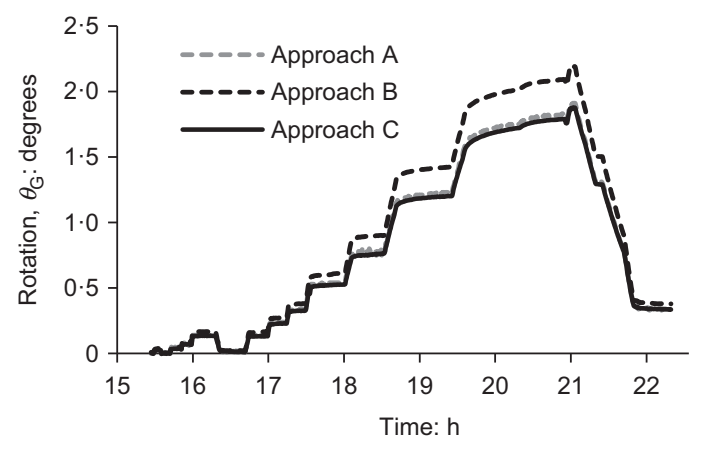

(b)

Fig. 8. Computed data on ground-level displacement and rotation for pile CM3 using approaches A, B and C: (a) displacement, $v_{G}$; (b) rotation, $\theta_{\mathrm{G}}$

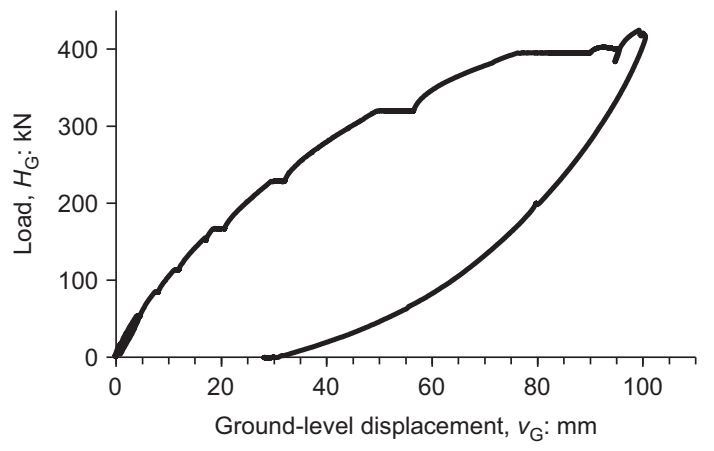

(a)

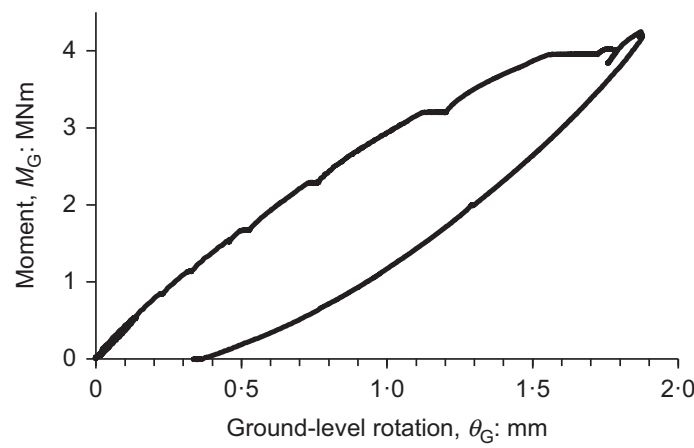

(b)

Fig. 9. Load-displacement and moment-displacement response for pile CM3 where $H_{\mathrm{G}}$ is the ground-level shear force $\left(H_{\mathrm{G}}=H\right)$ and $M_{\mathrm{G}}$ is the ground-level bending moment $\left(M_{\mathrm{G}}=H h\right)$ : (a) load-displacement; (b) moment-rotation

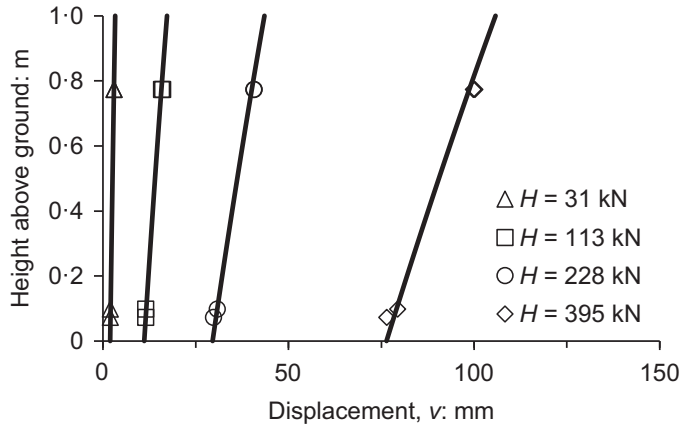

(a)

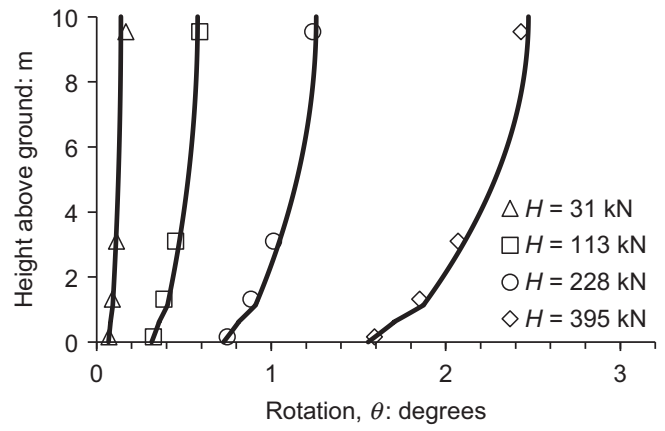

(b)

Fig. 10. Comparison between the optimised structural model (approach $\mathrm{C}$ ) and the measured displacements and rotations for pile CM3: (a) displacement; (b) rotation 


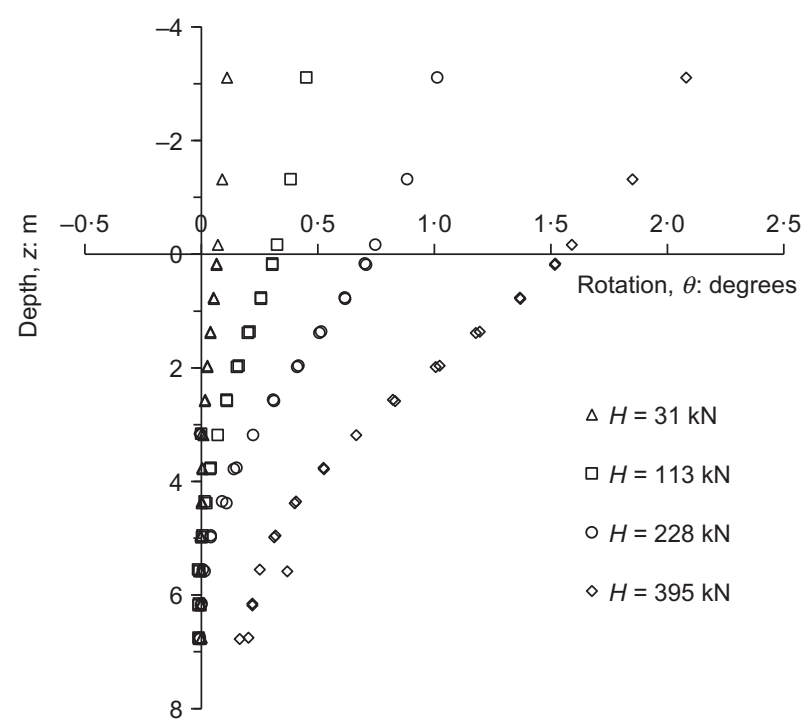

Fig. 11. Rotation profiles obtained from inclinometer measurements on pile CM3

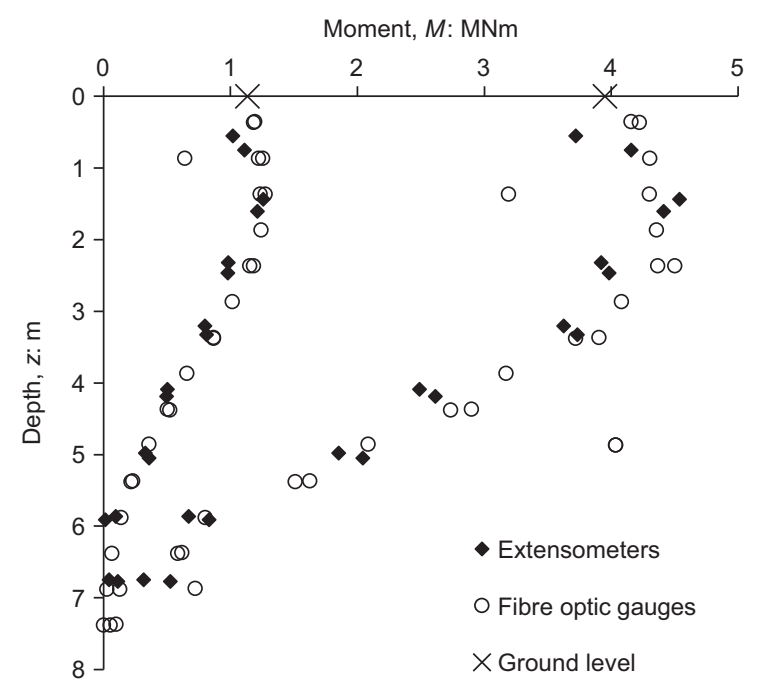

Fig. 12. Bending moments, deduced from the pile instrumentation, for pile CM3 at $H=113 \mathrm{kN}$ and $395 \mathrm{kN}$

were used to compute the local bending moment. Fig. 12 shows these inferred bending moments for two selected values of $H$. The fibre Bragg grating strain gauges provide a high-resolution bending moment profile, consistent with the ground-level moment determined from $M_{\mathrm{G}}=H h$, where $H$ is the load cell measurement. Experience gained from the tests suggests that the fibre Bragg grating strain gauge data were more reliable than the extensometer measurements. Although the extensometer data add some value (e.g. in providing redundancy), they were not systematically used in any subsequent data processing.

\section{CONCLUSIONS}

Key novel features in the PISA project testing set-up include the following.

(a) An elevated lateral loading mechanism: this allows a realistic application of combined horizontal load and overturning moment to the pile.

(b) Built-in fibre optic sensors along the pile wall: these mark a step-change in this type of field testing in terms of the quantity and quality of data from which to interpret more completely the mechanisms of pile-soil interaction. The successful use of fibre Bragg grating strain gauges installed in the pile wall prior to installation has been demonstrated. Despite initial fears that the optical fibres would become damaged during pile installation, the gauges provided a robust and successful means of recording the below-ground strains in the pile.

A new procedure for the determination of ground-level displacement and rotation from instrumented laterally loaded pile tests has been outlined and demonstrated. Procedures were developed to confirm the consistency of data from the instruments employed in the PISA test piles.

The methods outlined here were employed to process all of the field data obtained during the PISA project (Byrne et al., 2019; McAdam et al., 2019).

\section{ACKNOWLEDGEMENTS}

The PISA Project was funded by the UK Department for Energy and Climate Change (DECC) and the PISA industry partners under the umbrella of the Offshore Wind Accelerator (OWA) programme, which was designed and is led by the Carbon Trust. The authors acknowledge the provision of financial and technical support by the following project partners: Ørsted Wind Power (formerly DONG Energy), Alstom Wind, E.ON, EDF, Equinor (formerly Statoil), innogy, SPR, SSE, Vattenfall and Van Oord. The authors also gratefully acknowledge the work of Socotec UK Ltd (formerly ESG) as the main contractor for the design and execution of the field testing programme.

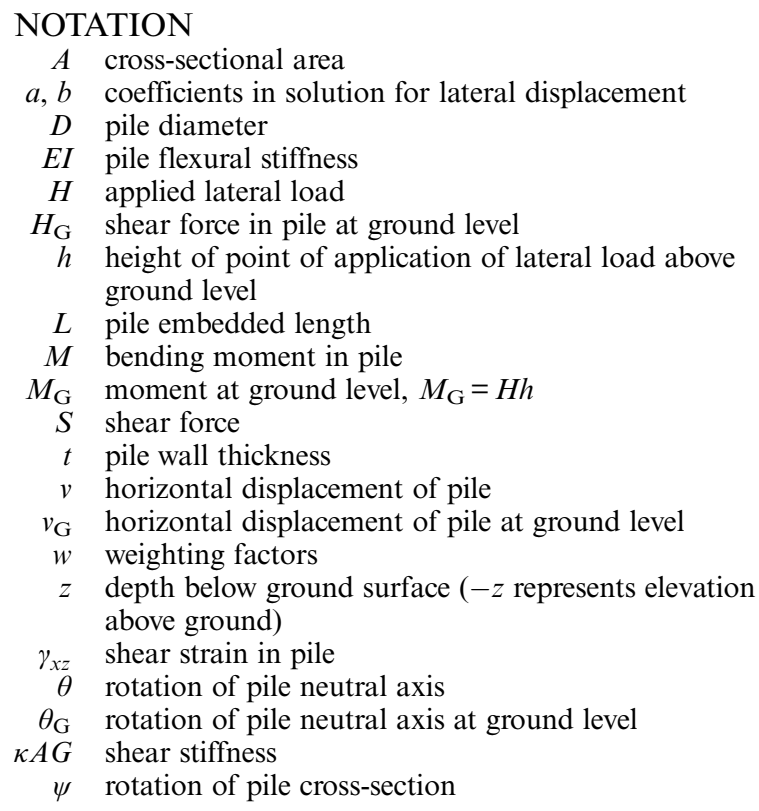

\section{REFERENCES}

Byrne, B. W., McAdam, R. A., Burd, H. J., Houlsby, G. T., Martin, C. M., Gavin, K., Doherty, P., Igoe, D., Zdravkovic, L., Taborda, D. M. G., Potts, D. M., Jardine, R. J., Sideri, M., Schroeder, F. C., Muir Wood, A., Kallehave, D. \& Skov Gretlund, J. (2015). Field testing of large diameter piles under lateral loading for offshore wind applications. In Geotechnical engineering for infrastructure and development: proceedings of the XVI European conference on soil mechanics and geotechnical engineering (eds M. G. Winter, D. M. Smith, P. J. L. Eldred 
and D. G. Toll), vol. 3, pp. 1255-1260. London, UK: ICE Publishing.

Byrne, B. W., McAdam, R. A., Burd, H. J., Houlsby, G. T., Martin, C. M., Beuckelaers, W. J. A. P., Zdravković, L., Taborda, D. M. G., Potts, D. M., Jardine, R. J., Ushev, E., Liu, T., Abadias, D., Gavin, K., Igoe, D., Doherty, P., Skov Gretlund, J., Pacheco Andrade, M., Muir Wood, A., Schroeder, F. C., Turner, S. \& Plummer, M. A. L. (2017). PISA: new design methods for offshore wind turbine monopiles. In Proceedings of the 8th international conference on offshore site investigation and geotechnics, smarter solutions for offshore developments, vol. 1, pp. 142-161. London, UK: Society for Underwater Technology.

Byrne, B. W., McAdam, R. A., Burd, H. J., Beuckelaers, W. J. A. P., Gavin, K. G., Houlsby, G. T., Igoe, D. J. P., Jardine, R. J., Martin, C. M., Muir Wood, A., Potts, D. M., Skov Gretlund, J., Taborda, D. M. G. \& Zdravković, L. (2019). Monotonic laterally loaded pile testing in a stiff glacial clay till at Cowden. Géotechnique, https://doi.org/10.1680/jgeot.18.PISA.003.

Chandrasekaran, S. S., Boominathan, A. \& Dodagoudar, G. R. (2009). Group interaction effects on laterally loaded piles in clay. J. Geotech. Geoenviron. Engng 136, No. 4, 573-582.

Doherty, P., Igoe, D., Murphy, G., Gavin, K., Preston, J., McAvoy, C., Byrne, B. W., McAdam, R., Burd, H. J. \& Houlsby, G. T. (2015). Field validation of fibre Bragg grating sensors for measuring strain on driven steel piles. Géotechnique Lett. 5, No. 2, 74-79, https://doi.org/10.1680/ geolett.14.00120.

McAdam, R. A., Byrne, B. W., Houlsby, G. T., Beuckelaers, W. J. A. P., Burd, H. J., Gavin, K. G., Igoe, D. J. P., Jardine, R. J., Martin, C. M., Muir Wood, A., Potts, D. M., Skov Gretlund, J., Taborda, D. M. G. \& Zdravković, L. (2019). Monotonic laterally loaded pile testing in a dense marine sand at Dunkirk. Géotechnique, https://doi.org/10.1680/jgeot.18.PISA.004
Parker, F. \& Reese, L. C. (1970). Experimental and analytical studies of behavior of single piles in sand under lateral and axial loading, Report number 117-2. Austin, TX, USA: Centre for Highway Research, University of Texas at Austin.

Reese, L. C., Cox, W. R. \& Koop, F. D. (1975). Field testing and analysis of laterally loaded piles in stiff clay. Proceedings of the offshore technology conference, Houston, TX, USA, paper OTC 2312.

Taborda, D. M. G., Zdravković, L., Potts, D. M., Burd, H. J. Byrne, B. W., Gavin, K. G., Houlsby, G. T., Jardine, R. J., Liu, T., Martin, C. M. \& McAdam, R. A. (2019). Finite element modelling of laterally loaded piles in a dense marine sand at Dunkirk. Géotechnique, https://doi.org/10.1680/jgeot. 18.PISA.006.

Zdravković, L., Taborda, D. M. G., Potts, D. M., Jardine, R. J., Sideri, M., Schroeder, F. C., Byrne, B. W., McAdam, R., Burd, H. J., Houlsby, G. T., Martin, C. M., Gavin, K., Doherty, P., Igoe, D., Muir Wood, A., Kallehave, D. \& Skov Gretlund, J. (2015). Numerical modelling of large diameter piles under lateral loading. In Frontiers in offshore geotechnics III (ed. V. Meyer), pp. 759-764. Leiden, the Netherlands: CRC Press/Balkema.

Zdravković, L., Jardine, R. J., Taborda, D. M. G., Abadias, D., Burd, H. J., Byrne, B. W., Gavin, K. G., Houlsby, G. T., Igoe, D. J. P., Liu, T., Martin, C. M., McAdam, R. A., Muir Wood, A., Potts, D. M., Skov Gretlund, J. \& Ushev, E. (2019a). Ground characterisation for PISA pile testing and analysis. Géotechnique, https://doi.org/10.1680/jgeot.18.PISA.001.

Zdravković, L., Taborda, D. M. G., Potts, D. M., Abadias, D., Burd, H. J., Byrne, B. W., Gavin, K. G., Houlsby, G. T., Jardine, R. J., Martin, C. M., McAdam, R. A. \& Ushev, E. (2019b). Finite element modelling of laterally loaded piles in a stiff glacial clay till at Cowden. Géotechnique, https://doi.org/ 10.1680/jgeot.18.PISA.005. 